\title{
Ideas claras sobre la libertad de enseñanza
}

\author{
Por Juan María LUMBRERAS MEABE \\ Profesor de la Universidad de Deusto (Bilbao)
}

Todos deseamos llegar a un "pacto escolar" entre los distintos partidos políticos, pero su plasmación se ha de hacer a la luz de la Declaración Universal de De* rechos Humanos y de los Pactos Internacionales, así como de la experiencia en el mundo libre, y su reali. zación será, sin duda, fruto de un proceso largo de maduración.

En estos meses se discuten en las Cámaras legislativas la Ley del Estatuto de Centros y la Ley de Financiación de la Educación. Con estas leyes orgánicas se desarrolla el artículo 27 de la Constitución, que "reconoce la libertad de enseñanza", si bien, al ser este artículo uno de los consensuados, con una ambigủedad que lo permite todo. De ello procede la importancia de ambas leyes y la necesidad de que los padres de familia conozcan y defiendan sus derechos y los de sus hijos y actúen unidos a fin de que la interpretación de estos derechos y libertades fundamentales se traduzca en normas que consagren la auténtica libertad de enseñanza.

\section{LOS DERECHOS HUMANOS Y LA DEMOCRACIA}

Los derechos humanos nacen con el hombre pues proceden inmediatamente de la dignidad intrínseca de toda persona humana. No son derechos concedidos, ni delegados, sino propios. Se dice que "todos nacemos con un pan debajo del brazo", pero la experiencia demuestra que esto no es verdad. Pero sí lo es que todos venimos al mundo con un haz de derechos y libertades fun. damentales inherentes al mismo ser de la persona, por ser necesarios para su desarrollo y perfeccionamiento en la vida social. 
Estos derechos-la lista continúa abierta-han sido codificados por la O.N.U. en la "Declaración Universal de Derechos Humanos" (10 de diciembre de 1948). Posteriormente, el Consejo de Europa elaboró el "Convenio Europeo para la protección de los Derechos Humanos" (4 de noviembre de 1950) y la O.N.U. el "Pacto Inter. nacional de Derechos Económicos, Sociales y Culturales" $(16$ de noviembre de 1966) y el "Pacto Intemacional de Derechos Civiles y Politicos" (16 de noviembre de 1966) (1). Todos ellos han sido ratificados por el Estado Español que se ha comprometido libre. mente a guardarlos (2).

Los derechos humanos y las libertades fundamentales son per* sonales, brotados de la misma dignidad de la persona y, por ello, son anteriores a los grupos sociales, a la sociedad civil y al Estado, que deben reconocerlos, garantizarlos y darles una viabilidad efectiva. por ello, los derechos humanos, las libertades fundamentales, no estan sujetos al voto de la mayoría, "ho son negociables", sino inviolables, y constituyen el estatuto de autonomía de todá persona humana, que ha de ser respetado siempre.

La quintaesencia de un régimen político democrático consiste en el respeto. la salvaguarda efectiva y el esfuerzo continuo por hacer real, a todos y a cada uno de los seres humanos, el ejercicio de sus derechos y libertades fundamentales, en lo que consiste el bien común. Un sistema político que los negara o dificultara su ejercicio nada tendría de democrático, por mucho que alardea. ra de ello. $Y$ toda reforma que se presentara como muy democrática, pero impidiera el ejercicio de los derechos de las personas concretas, sería la negación de la democracia. No son las personas para los grupos, la sociedad o el Estado, sino estas instituciones para posibilitar y faclitar, mediante el ejercicio de los derechos humanos y el cumplimiento de las obligaciones fundamentales, el desarrollo y perfeccionamiento de cada persona, que siempre ha de ser "el fundamento, el sujeto y el fin de la vida social".

(1) La Declaración Universal fija una meta a la que los Estados todos de la O.N.U. tienen la obligación moral de tender, de aspirar; el Convenio Europeo y los Pactos Internacionales concretan y detallan los derechos y liber. tades de la Declaración, pero, sobre todo, por ellos los Estados, libremente firmantes, se comprometen jurichicamente entre si a respetarlos y hacerlos efectivos.

(2) La Constitución, en su artículo 10.2, establece: "Las normas relativas a los derecho fundamentales y a las libertades que la Constitución reconoce, se interpretarán de conformidad con la Declaración Universal de Derechos Humanos y los tratados y acuerdos internacionales sobre las mismas materias ratificados por Españan y, en sti artículo 96,1: "Los tratados internacionales válidamente celebrados, una vez publicados fílolalmente en España, formarán parte del ordenamiento interno. Sus disposiciones sólo podrán ser derogadas, modificadas o suspendidas en la forma prevista en los propios tratados o de acuerdo con las normas generales del Derecho internacional." 


\section{EL DERECHO A LA EDUCACION}

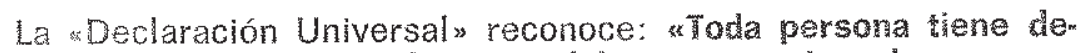
recho a la educación. La educación debe ser gratutata, al menos en lo concernente a la instrucción elemental y wundarnental. La ins" tracción elemental será obligatoria...» (Art. 26.1).

El ser humano al nacer es débil e impotente y su conducta futura, a diferencia de los animales, no está programada en su código genético, por lo que necesita imprescindiblemente de una educación larga para desarrollarse como persona y poder cumplir su misión personal y social. La educación, en consecuencia, ha de ser obligatoria en los niveles básicos y, para que ello sea efectivo para todos, debe ser gratuita en estos niveles. Así lo prescribe nuestra Constitución: Todos tienen derecho a la educación... La enseñanza básica os obligatoria y gratuita» (Arts. 1 y 4 ).

Notemos que la obligatoriedad y la gratuldad es un derecho de los alumos "dada la necesidad que tienen de una instrucción y una educación que les capaciten como futuros profesionales y les faciliten como hombres el pleno desarrollo de su personalidad humana, el sentido de su dignidad, el respeto a los derechos y libertades fundamentales de los demás, y favorezcan la comprenslón, la tolerancia, el diálogo, la solidaridad y la particlpación efectiva en una sociedad libre. Esta educación, además, para ser humena, ha de ser integral, sin que descuide ninguna de las dimensiones esenciales del hombre: intelectual y técnica, volitiva y afectiva, corporal y sanitaria, social y convivenclal, estética, filosófica, moral y religiosa.

\section{EL DERECHO DE LOS PADRES DE FAMILIA}

La "Declaración Universal" proclama: «os padres tandrán el derecho preferente a escoger el tho de educacion aus habú de darse a sus hipos" (Art. 26.3.); el "Pacto Intemacional de los Derechos económicos, sociales y culturales": "Los zstados Parres... sa comprometen a respetar la libertad de los partros y, en su caso, de los tutores legales de ascoger para sus hilos o phollos escue las distintas de las creadas por las autoridades publichas... y hacer que sus hilos o puollos reciban la educación religíosa o moral gue esté de acuerdo con sus propias convicciones" (Art. 13.3); y la

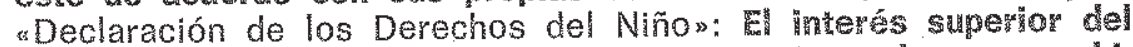
niño debe ser el principho rector de quitenes tenen la responsabilidad de su educación y de su orientación; diche responsablided nowmbe en primer lugar a sus padres a (Principio VII, 2:; O. N.U., 20 de noviembre de 1959).

De la lectura de estos textos se deducen una serie de consecuencias: 


\section{」. M. LUMBRERAS MEABE}

1.2) que el derecho de los padres es preferente, prioritario, respecto a los Centros educadores, a los profesores, a la sociedad y a los poderes públicos regionales, nacionales y estatales. No es un derecho exclusivo, pero sí el primero, el preferente, en orden a elegir la orientación de la educación de sus hijos, el modelo educativo,

2.i) que el derecho de los padres es personal, es decir, propio de las personas físicas concretas: el padre y la madre, que son los unicos que han engendrado a sus hijos. No se puede entender, como se hace continuamente, el término "padres" en sentido colectivo: la Asociación de Padres de Alumnos del Centro, la Asociación de Padres local, regional, estatal $y$, mucho menos, las Asociaciones de Vecinos, sindicatos o partidos políticos. Todas estas instituciones juridicas no han engendrado, ni pueden, a los alumnos, sino a cada uno su padre y su madre,

3.) que el derecho preferente del padre y de la madre no se reduce, con ser importantísimo, a "la formación religiosa y moral", como lo hace nuestra Constitución (Art. 27.3). Sus motivos abar. can un campo mucho más amplio: la formación religiosa y moral, si, pero también todo lo que comprende el término "el tipo de edu. cación": orientación filosófica, métodos pedagógicos, organzación, responsabilidad y seriedad le Centro $y$, como lo dice expresamente el Pacto, la titularidad del Centro, sea creado por las autoridades públicas, o por personas no públicas, físicas o jurídicas, confesionales o no,

4.) que este derecho del padre y de la madre no está sujeto al voto de la mayoría. No serían libres el padre y la madre para elegir el tipo de educación de sus hijos, si debieran aceptar, acatar, la orientación que por votación mayoritaria decidiera el con junto de los padres y de los profesores. Esta fórmula, presentada como muy democrática, es la negación de la democracia. Anula uno de los derechos y libertades humanos fundamentales: el de los padres de familia.

Claro que para que este derecho de los padres sea real, y no puramente formal, son necesarias dos condiciones: 1.2) la identidad y pluralidad de los Centros y 2.") la gratuidad de la enseñanza en los niveles básicos y la igualdad en los no obligatorios.

\section{EL. DERECHO DE LAS PERSONAS E INSTITUCIONES}

El "Pacto Internacional de los Derechos económicos, sociates y culturales. declara y proclama: Nada de 10 dispuesto en este articulo se interpretará como una restricción de la libertad de los partichares y entudades para establecer y dirigh instituciones de ensenanza, condicion de que se resperen los principlos enzaricia* 
dos en el párrafo 1 y de que la educación dada en estas instituciones se ajuste a las normas mínimas que prescribe el Estado" (Artículo 13.4).

El derecho de las personas físicas o jurídicas a crear y dirigir Centros de enseñanza y educación nace de un haz de derechos y libertades fundamentales emanados de la misma dignidad de la persona humana. Tales son la libertad de pensamiento, la libertad de expresión, la libertad de conciencia, el derecho a participar en la creación y la difusión de la cultura, la libertad de asociación y la libertad religiosa. Derechos y libertades todos ellos no otorgados, concedidos o delegados, sino propios, personales, anteriores e inviolables, de los que nace, como un fruto espontáneo, el derecho a crear y dirigir Centros educadores. El derecho a crear y dirigir Centros no procede, por tanto, ni del principio de libertad de empresa, ni del derecho a la propiedad privada-es posible educar sin la materialidad del Centro-. Las raices son más hondas: la misma esencia de la dignidad de todo ser humano.

La diversidad existencial de los seres humanos y la igualdad jurídica de todos conducirán a la creación de una amplia gama de tipos de Centros en la sociedad-sin pluralidad en la sociedad no hay libertad, ni democracia-. Cada Centro podrá tener su concepción específica propia del sentido último del hombre, del mundo, de la vida, de tipo filosófico o/y religioso, que intentará imprimir a la educación que imparte y cuyos principios y valores estarán plasmados en lo que se ha llamado el Ideario del Centro. El Ideaflo no es una ideología, ni mucho menos un programa politico, sino la explicitación de una visión última de la existencia, que nos oriente filosófica o/y religiosamente en los más hondos problemas humanos: ¿qué somos?, ¿de dónde venimos nosotros, el universo?, ¿cuál es nuestro papel, nuesta misión en la vida, en la sociedad, en la Historia?, ¿a dónde vamos?, ¿cuál es nuestro destino final, nuestro más allà? La libertad conlleva necesariamente la pluralidad de Centros en la sociedad, cada uno con su carácter e identidad propias, aunque muchos puedan coincidir. El derecho de los creadores de los Centros a dirigirlos entraña la identidad del Centro y su permanencia a fin de cumplir su compromiso con los padres, que, por ello, lo han preferido en conciencia para sus hijos.

Así es, aunque el artículo 27.6, tras largas disensiones, retiradas, amenazas y consensos, sintomáticamente suprimió la palabra "dirigir".

A este respecto conviene hacer algunas aclaraciones:

1.) Los creadores de los Centros con Ideario especifico no imponen a los padres-como continuamente se repite-su concepción de la vida. Nada de eso. Sólo ofrecen un determinado tipo 
de educación para que los padres que to prefieran libremente puedan elegir. Sin pluralismo, la libertad de elección es imposible. Entre cosas iguales no se escoge, se coge.

2.9) Tampoco violan los derechos de los profesores-como se dice-ya que la diversidad de Centros en la sociedad permiť a los profesores enseñar en aquellos cuya orientación coincida con sus convicciones y creencias.

3.) Estos Centros no estatales, llámeseles así, o "privados", o "libres", prestan a la sociedad un servicio de interés público muy considerable. No solo educan a más de tres millones de alumnos, el 40 por 100; ni sólo son el instrumento y la expresión de la libertad de enseñanza; sino que, además, estimulan la competencia de la enseñanza estatal, lo que redunda en la mejora de la calidad de ambos sectores. Pero, a pesar de todo ello, tales Centros no son públicos, officiales, sino privados, libres, no estatales. No ha habido una asunción en exclusiva por parte del Estado de la titularidad de la función educadora, una estatificación de la enseñanza, en cuyo caso actuarian aquéllos, por concesión, por delegación, ni puede haberla en un régimen democrático respetuoso de las libertades fundamentales. Sería anticonstitucional.

4.9) Tales Centros no estatales, en su inmensa mayoría, no son empresas con axán lucrativo, como se les calumnia, sino instituciones, que necesitan, sí, cubrir los cuantiosos y crecientes costes de la enseñanza, pero que desean fundacionalmente prestar un servicio educacional a los niños, jóvenes y adultos que los solicitan, de todas las clases sociales. Felipe González dijo: "Yo nunca he creido eso de la 'enseñanza negocio'. Sé que no lo es. No to he creido nuncan (3).

\section{LA GRATUDAD DE LA ENSENA ANZA}

La "Declaración Universal" establece: "La educación debe ser gratuita al menos en lo concemiente a la instrucción elemental y fundamental" (artículo 26.1) y el "Pacto internacional de los Derechos económicos, sociales y culturales": "Los Estados Partes en el presente Pacto reconocen que con objeto de lograr el pleno ajercicio de este derecho: a) La enseñanza primaria debe ser obligatoria y asequible a todos gratuitamente" (artículo 13.2.a) y rtodo Estado Parte en el presente pacto cuse, en el momento de hacerse parte en él, aún no haya podido instiun en su rerritorio.. la oblin gatoniedad y la gratuidad de la enseñanza primaria, se compromete a elaborar y adopiar, dentro de un plazo de dos años, un plan detallado de acción para la aplicación progresiva, dentro de un numero razonable de años tijado en el plan, of principolo de la enseñanza

(3) Blanco y Negro, núm. $3.539,27-11-1980$. 
obligatoria y gratuita para rodos" (artículo 14) y nuestra Constitución: «La enseñanza básica es obligatoria y gratuita» (art. 274.).

De todos los textos internacionales y de nuestra Constitución se deduce:

$\left.10^{\circ}\right)$ Que los thtulares de la gratuidad son los allumnos, a fin de que sea asequible efectivamente a todos el derecho a la educación y, en segundo lugar, los padres de familia para que todos ellos, aun los de menos posibilidades económicas, tengan la libertad real de elegir el tipo de educación y el Centro educador de sus hijos, estatal o no, confesional o no, de esta o de otra confesión. Sin gratuidad para todos no habría libertad efectiva de elección para la mayoría de los padres: los económicamente débiles y los padres de familia numerosa (4).

El que aún haya un número de padres, cada vez menor, que por vivir en municipios muy pequeños, no tenga, de hecho, libertad de elección no es argumento válido para negar este derecho básico de todos los padres, sino para buscar soluciones excepcionales en estos casos, que tienden a desaparecer por el proceso migratorio de la población: podrán ser la creación de escuelas comarcales, hogar, etc., en poblaciones mayores con pluralismo escolar; y en el caso de que ni aun esto sea viable, se ha de extremar el respeto a la conciencia de los alumnos y de sus padres. Dar fuerza a ese argumento-como se hace-sería, algo así, como intentar negar el derecho de toda persona a la vida, al trabajo, a la educación, a la vivienda, etc., porque hay una minoría de hambrientos, de parados, de analfabetos, de vagabundos... Los derechos humanos no describen lo que pasa, lo que es, como la estadística, sino lo que debe ocurrir, lo que debe ser. Nacen, no de las circunstancias externas, sino del hombre mismo en sí considerado.

2.9) Oue los alumnos y sus padres tienen, además, derecho a la gratuidad por razones de igualdad. Como proclama nuestra Constitución: "los españoles son iguales ante la ley sin que pueda prevalecer discriminación alguna por razón de nacimiento, raza, sexo, religión, opinión o cualquier otra condición o circunstancia personal o social" (arts. 1 y 14). Sería discriminador, injusto y anticonstitucional la no extensión de la gratuidad a los alumnos y pa-

(4) Aunque tópicamente se dice, los alumnos de los Centros no estatales no son los ricos. Según el informe F.O.E. S. S. A., la clase atra española (e) 0,5 por 100) y la clase mediamalta (el 6 por 100) son el 6,5 por 100 de la poblax ción, por lo que, al sor ésta de 37 millones, pertenecen a dichas clases ricas $2.405,000$ españoles. De éstos, aplicándoles la media etropea, están escolarizados ol 25 por 100 -en Espańa es aún del 22,9 por 100 , es decir, 601.250 alumnos. Aun suponiendo que todos frecuentaran la enseñanza no estatal-lo cue es falso-y siendo 3.279 .500 los alumnos no estatales, resulta que 2.678 .300 de estos alumnos pertenecen a la clase medía-media, a la mediabaja y pobre. En otras palabras, el 82 por 100 , las cuatro quintas partes de su alumnado, son de estas clases y sólo el 18 por 100 , una quinta parte, de la clase rica. 
dres que, ejercitando un derecho propio fundamental, hayan ele gido un Centro no estatal.

3.) Que, finalmente, todos los padres de familia y sus hijos tienen derecho a la gratuidad en los niveles obligatorios y a la igualdad en los niveles no obligatorios por razón de justicia dis. uributiva. Todos son ciudadanos a la hora de contribuir progresivamente a formar los fondos públicos y todos deben serlo por igual a la hora de la distribución. El Estado no es la fuente ni el dueño de los fondos públicos, sino el administrador de unas cantidades que proceden y pertenecen a todos los ciudadanos, de los que, además, "emanan los poderes del Estado" (Const, art. 1.2). Es contrario a la justicia distributiva eliminar de la gratuidad en los niveles básicos y de la igualdad en los no obligatorios a los alum. nos y padres que prefieren y frecuentan los Centros no estatales, convirtiéndolos en ciudadanos de segunda caregoría y obligándoles a pagar la educación de sus hijos por partida doble: 1. ${ }^{\circ}$ con los impuestos al Estado y 2.') con los honorarios a los Centros. "Contribuir da derecho a exigir" dice el "slogan" de Hacienda.

4.) Que, consiguientemente, los Centros educadores no estatales no son los intulares de la gratuidad. Lo son los alumnos y los padres de familia y a ellos deben ir directamente los fondos públicos mediante cheques o bonos escolares para que los entreguen a los Centros que han preferido en conciencia. De hecho el Estado no lo ha hecho así y, por razones de economía y de simplicidad administrativa, entrega los fondos públicos directamente al Centro no estatal. Pero debe quedar claro que los titulares de la gratuidad y de la igualdad son los alumnos y los padres, no los Centros $y$, sobre todo, que el que la Administración utilice, se sirva, de los Centros para implantar la gratuidad en nada debe hipotecar, como se pretende con soffismas, el carácter de no estatal, no público, del Centro, y su identidad específica. Pretender, a cambio de ese servicio impuesto al Centro, que renuncie a su carácter propio, que sea aconfesional, autogestionado y pluralista, es injusto, abusivo, y un atropello incalificable a una de las libertades fundamentales: la libertad de enseñanza.

Los Centros no estatales, estén subvencionados o no, admiten y desean la dirección participada, es decir, la participación de los padres y profesores, asi como del personal no docente, en la gestión del Centro por ser un imperativo de su dignidad personal y un requisito para crear una comunidad educativa, pero siempre ha de quedar a salvo la existencia y la identidad diferenciada del Centro, sin lo cual sería inviable la libertad de enseñanza.

\section{CONCLUSION}

Todos sabemos que frente a la libertad de enseñanza que prom pugnamos se presenta otra altemativa que, en nombre de la li- 
bertad, de los derechos fundamentales y de la democracia, defiende un modelo de sistema cuyas notas caracteristicas serian: $1 .{ }^{2}$ ) la

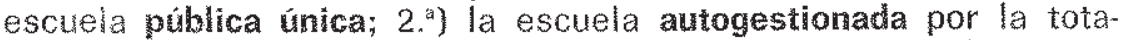
lidad de los profesores, de los padres y, en su caso, de los alumnos, cue elegirian el director y contratarian los profesores sin discriminaciones ideológicas, filosóficas, políticas, morales, religiosas, etc.; y $3 .^{a}$ ) la escuela ideológicamente pluralista en el interior de cada Centro.

A la luz de las ideas claras expuestas, es fácil comprobar que tal sistema es la negación de la libertad de enseñanza y la supresión de los derechos y libertades básicos, tales como se exponen en la Declaración Universal, en los Pactos Internacionales y en el Convenio Europeo. No se respetaría el derecho de toda persona a una educación integral, armónica y liberadora, ya que el pluralismo interno en el Centro conduciría al niño y al joven, aún sin capacidad para analizar, criticar y sintetizar tantas opiniones, al confusionismo, al escepticismo y/o al nihilismo. Tampoco sería viable el derecho del padre y de la madre a elegir el tipo de educación de sus hijos, pues una escuela autogestionada y pluralista no puede ofrecer un tipo de educación determinado y permanente, sin lo que es imposible la elección en firme, ya que estaría sujeta al juego carnbiante de la mayoría. $\mathrm{Ni}$, finalmente, los creadores de los Centros podrían dírigirlos en función de un ldeario, ya que la autogestión sustrae la direccción al creador del Centro y el pluralismo esfuma el Ideario.

Todos deseamos llegar a un "pacto escolar" entre los distintos partidos políticos, pero su plasmación se ha de hacer a la luz de la Declaración Universal y de los Pactos Internacionales, asi como de la experiencia en el mundo libre, y su realización será, sin duda, fruto de un proceso largo de maduración.

25 de abril de 1980. 